\title{
Logistics in Namibia: Issues and challenges
}

\begin{abstract}
Authors:
Christopher J. Savage

Logan Fransman ${ }^{1}$

Andrew K. Jenkins ${ }^{2}$

Affiliations:

${ }^{1}$ The Namibian German Centre for Logistics,

Polytechnic of Namibia,

Windhoek, Namibia.
\end{abstract}

${ }^{2}$ Business Operations, Supply Chain and Transport Research Group, University of Huddersfield, West Yorkshire, United Kingdom.

\section{Correspondence to:}

Christopher Savage

Email:

csavage@polytechnic.edu.na

\section{Postal address:}

Private Bag 13388, No. 3

Haydn Street, Windhoek-

West, Windhoek, Namibia

\section{Dates:}

Received: 03 Dec. 2012

Accepted: 11 June 2013

Published: 06 Aug. 2013

How to cite this article: Savage, C.J., Fransman, L. \& Jenkins, A.K., 2013, 'Logistics in Namibia: Issues and challenges', Journal of Transport and Supply Chain Management 7(1), Art. \#86, 8 pages. http://dx.doi. org/10.4102/jtscm.v7i1.86

\section{Note:}

This article is based on the book publication and shares some material of: Savage, C.J., Fransman, L. \& Jenkins, A.K., (2012), Logistics in Namibia: Issues and challenges, The Polytechnic of Namibia, Namibia.

\section{Copyright:}

(C) 2013. The Authors.

Licensee: AOSIS OpenJournals. This work

is licensed under the Creative Commons

Attribution License.

\section{Read online:}

Logistics is perceived to be important for Namibia's growth and development, but this may be a matter of conjecture as there is a dearth of documented information about the industry in Namibia. Furthermore, it is uncertain what the understanding of logistics is for key stakeholders in the country. This article reports on a project; the objectives were to address some of these issues and to lay the foundation for a more thorough investigation in the future. The findings of the initial project were disseminated in 2012 by: a conference paper showing the challenges and opportunities facing logistics in Namibia in 2012; a report; and through a Logistics and Transport Workshop held in Walvis Bay, Namibia in September 2012. These reports, additional interviews and subsequent discussions highlighted some potential opportunities and problems. This article summarises the project to date, showing the methodology and findings as updated by subsequent feedback and further interviews. The findings from key stakeholders of the logistics industry in Namibia include: universal agreement on the importance of logistics to Namibia; the variety in the understanding of the term logistics; the strength of the continuing influence of South Africa as the dominant economic power in southern Africa; and contrasting views on the main factors limiting logistics development, including infrastructure, attitude, government, customs, training, railways, corruption and driver shortage.

\section{Introduction}

The purpose of this article is to identify and explore contemporary issues and trends in the Namibian logistics industry. In order to further develop the logistics industry in Namibia it is necessary to identify the trends and issues affecting it. This article attempts to address the research question: 'What is the current state and potential for the development of Logistics in Namibia?' This is underpinned by four subsidiary questions, namely:

- What are the stakeholders' views on the current state of the Namibian logistics industry?

- What are the principal logistical issues in the stakeholder's firm or organisation?

- What do stakeholders believe are the barriers and key issues affecting the operations and development of the logistics industry in Namibia?

- What are stakeholders' views on the sustainability of the Namibian logistics sector?

For this research, the stakeholders identified were users, logistics companies, freight forwarders, the Namibian state, logistics service providers (LSPs) and transport firms. For context, this article will present an overview of Namibia, including political, economic, socio-cultural and technological developments as well as a discussion of the current transport and logistics industry. It then presents the research methodology.

Namibia is a sparsely populated sub-Saharan country with approximately 2.3 million inhabitants. It is a country similar in size to Mozambique (World Bank 2009; figures relate to 2010). Namibia is categorised as an upper-middle-income country (World Bank 2012b). In 2010, gross national income per capita purchasing power parity (PPP) was US\$6 420 (World Bank 2009). The country has one of the highest levels of income inequality of any country (African Development Bank 2007). An accepted way of measuring income inequality is the Gini-coefficient, which ranges between 0 (complete equality) and 1 (complete inequality) (World Bank 2012a). According to the latest (2009/2010) household survey, Namibia's Gini-coefficient is 0.58 , which is one of the highest in the world (World Bank 2012a).

Namibia's economy is closely linked to South Africa's (African Development Bank 2007), with the Namibian Dollar being pegged at a ratio of 1:1 to the South African Rand (World Bank 2009). South Africa plays an important role in logistics for neighbouring countries such as Namibia; this is because it has the most developed infrastructure and logistics skills in Africa and functions as a gateway for southern Africa (Cilliers \& Nagel 1994). Approximately $80 \%$ of Namibia's total imports are from or through South Africa (African Development Bank 2007). Moreover, South 
Africa's wealth and critical mass enable her to exercise a great deal of influence on Namibia (Clerck 2008). It has also been reported that some South African companies register 'daughter' companies in Namibia that are 'legally Namibian' thus allowing them to exert significant control.

The Republic of Namibia's Vision 2030 strategy (Republic of Namibia 2004) recognised the importance of a welldeveloped infrastructure for the country's industrialisation. Furthermore, the 3rd National Development Plan, 2008 (NDP_3) identified the goal of establishing and sustaining a well-developed and reliable infrastructure in order to improve competitiveness, increase productivity and reduce production costs (National Planning Commission 2008). Of particular importance was the development of the road network because it influences access to markets (Cilliers \& Nagel 1994). The recently published National Development Plan 4 NDP_4) for $2012 / 2013$ to $2016 / 2017$ (released in 2012) set logistics and infrastructure as important priorities (National Planning Commission 2012). Clearly, the Namibian government considers logistics to be important for the development of the country as part of the Southern African Development Community (SADC). The development of an efficient transport system is important for Namibia, as it is for all Sub-Saharan counties, so that the flow of goods can be improved (Voordijk 1999).

In 2010, Namibia had $64189 \mathrm{~km}$ of roadways $(5477 \mathrm{~km}$ was paved), $2626 \mathrm{~km}$ of railways, 21 airports with paved runways and two ports: Walvis Bay and Luderitz (CIA 2012). Container port traffic in Namibian ports amounted to 256 319 TEU (twenty foot equivalent units) (World Bank 2012b). Namport is the parastatal authority that manages both ports, which together handle more than 2.5 million metric tonnes of cargo a year (NAMPORT 2012). The Port of Walvis Bay is being expanded with the addition of a new container port, planned for completion in 2014, which will cater for an additional 500000 TEU (Namibian Ports Authority Annual Report [NAMPORT] 2009/2010) and has an expectation of reaching a capacity of $1 \mathrm{M}$ TEU in the near future. The value of the transport sector has increased by an average of $8.7 \%$ (of GDP) per annum for the five years between 2005 and 2010; this was attributed to the increase in volumes through the port of Walvis Bay, cross border trading and the mining sector (NEPRU 2010).

TransNamib Holdings Ltd. is a wholly owned parastatal of the Republic of Namibia that specialises in the transport of bulk and containerised freight by rail and road whilst also offering some rail passenger services (TransNamib 2012). The state airline, Air Namibia, in addition to providing passenger services to domestic and international destinations, offers freight services from Windhoek (the capital of Namibia) to Frankfurt, Cape Town, Johannesburg, Luanda and various destinations within Namibia (Air Namibia 2012).

The key findings of this research are discussed in the following section and the article will end with a conclusion and recommendations for further work.

\section{Research strategy}

This study focuses on exploring the contemporary issues and trends in the Namibian logistics industry. As there is a dearth of published information on this topic, the research design is primarily explorative with the objective of establishing a focus for future work (Blumberg, Cooper \& Schindler 2011).

\section{Research approach}

The research design is primarily explorative with the objective of establishing a focus for future work (Blumberg et al. 2011). It utilises a qualitative approach, centred on exploring the meanings of situations and events for participants in the research (Clarke 2003). Semi-structured interviews were used to obtain information from the main stakeholders about key areas. This allowed the exploration of emergent issues in greater depth whilst remaining able to react to individual respondents. Semi-structured interviews were chosen as the principal method of collecting primary, qualitative data where the major questions were the same in each interview, but where the interviewer was free to alter the sequence of questions and probe for greater detail (Fielding \& Thomas 2003). A guide was developed for the interviewer that addressed general information about the organisation, management and operations, cost and time management, technology and infrastructure and future issues for the organisation and the country (Namibia). Most questions were qualitative in nature, but semi-quantitative questions were used where the topic lent itself to estimation of the company's (or country's) relative position in terms of a particular subject.

\section{Participants or respondents}

Organisations were purposefully selected from various directories in order to reflect the type of stakeholder and geographical diversity in Namibia; they were asked to nominate interviewees. The use of such a non-probability sampling design is suitable for exploratory research (Blumberg et al. 2011), as the objectives for this research did not require generalisations and statistical estimations (Saunders, Lewis \& Thornhill 2007). A total of 25 interviews were undertaken in this first phase of the research.

Interviews typically lasted between $45 \mathrm{~min}$ and $60 \mathrm{~min}$ and were conducted face-to-face at the interviewee's place of work.

\section{Methods of data gathering and treatment of data}

The interviewer took detailed notes. They were subsequently transcribed and analysed using the data matrices approach as recommended for cross-site, qualitative data analysis by Nadin and Cassell (2004). The aim of this method was to produce a complete matrix, where similarities or differences could be analysed by row or column. Once the data had been transcribed and coded, the following steps were undertaken: 
- The transcripts were read and re-read.

- The categories and sub-categories were generated by recording frequently occurring themes. The resulting topics were then analysed in order to distil meaningful groups or classes.

- Sections of the interview transcripts were allocated to the different categories and sub-categories.

- The data were analysed for each category and subcategory.

Once the interviews had been transcribed and the data coded, they were transferred to a large matrix so that the team of analysts could identify key categories and sub-categories. An advantage of using data matrices is that they provide accessibility to large amounts of qualitative data, although the technique is time consuming and may be too reductionist (Nadin \& Cassell 2004). In this case, although the provisional stakeholder groups were associated with each interview, the data were examined in their entirety to determine factors that related to categories and sub-categories, irrespective of the source. Subsequently, it was possible to compare the responses by stakeholder group in order to check for commonality and differences. Furthermore, by creating 'cross-category

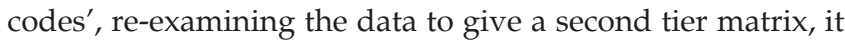
was also possible to see if the data contained other relevant groupings besides those of the initial stakeholders identified by the team. The use of multiple analysts was intended to remove any interviewer bias, whilst the combination of data in the second tier matrix gave the opportunity to discard any outlying values and ensure cross-rater reliability as far as possible.

The provisional stakeholder groups identified included:

- Users - organisations that depend on logistics to support their core activities (and have a major influence on supply chains) for example, retailers.

- LSP (logistics service providers) - this group ranged from organisations offering transport and warehousing to full 3rd or 4 th party logistics services (3 or 4 PLs). The latter organisations, which take a higher-level view of operational logistics systems, may or may not own some or all of the assets used to provide the service.

- Freight forwarders - companies specialising in facilitating the movement of goods across international borders.

- General facilitators - organisations dedicated to promoting trade that has, or is supported by, some logistics content.

- Government - representatives of the relevant ministries, the Roads Authority, etc.

- Parastatals - organisations or industries, especially in some African countries, that have some political authority and serve the state indirectly (Oxford Dictionaries 2012).

- Transport operators - companies whose core business is transport rather than logistics service provision (N.B. some may offer limited warehousing or other services, but their focus is on transport and they generally only move goods under the direction of other parties).

For Phase I analysis these were aggregated into four groups: Users; LSPs and freight forwarders; Transport operators; and others (including government and parastatals). Table 1 shows the number of interviews conducted and classified by the different stakeholder groups.

\section{Discussion}

The findings are based on the comments made by interviewees, all of whom were Namibian or Namibian residents and had a stake in the logistics industry. The interviews were explorative in nature and the interviewees, or rather their organisations, were selected on a purposeful basis to try to cover a range of stakeholder views. The breadth of coverage was considered to be as equally important as depth in order for the researchers to build up a comprehensive overview of the perceptions of Namibian logistics. Despite the wide range covered, the research revealed significant themes and trends as well as exposing similarities and differences in the views held both across and within the stakeholder groups. Where possible, similarities and differences were examined to try to determine their probable causes, identify areas where further work is required and establish foci for future work.

During the interviews, as well as commenting on the state of logistics and its sustainability, respondents were asked to look forward to identify and prioritise actions that they believed would overcome the barriers and take Namibian logistics successfully forward into the 21st century. This section will review the findings and the respondents' suggestions.

\section{Importance of logistics to Namibia}

Logistics was generally regarded to be extremely high and some people seemed to be quite optimistic. A parastatal representative felt that 'Namibia punches above its weight in logistics terms and has been responsible for changing some of the old established trading routes'; thereby suggesting that Namibia and her logistics industry have an influence upon other, much larger countries. Similarly, a freight forwarder stated that 'Namibia has a great harbour in Walvis Bay as well as the corridor groups that give it the potential to act as the main supply channel for imports to itself and other countries in the region'. Figure 1 shows the main corridor routes of southern Africa. On the other hand, some people were very concerned about the 'lack of a level playing field for transport operators', which they felt existed partly because of a 'lack of government concern and knowledge about the role and importance of logistics to Namibia'.

\section{Geography}

Logistics is influenced by geography and the history of the country. The most frequently occurring issues are related

TABLE 1: Number of interviews per stakeholder group.

\begin{tabular}{ll}
\hline Stakeholder group & Number \\
\hline Users & 9 \\
LSPs and freight forwarders & 5 \\
Transport operators & 6 \\
Government, parastatals and others & 5 \\
\hline Total & $\mathbf{2 5}$ \\
\hline
\end{tabular}




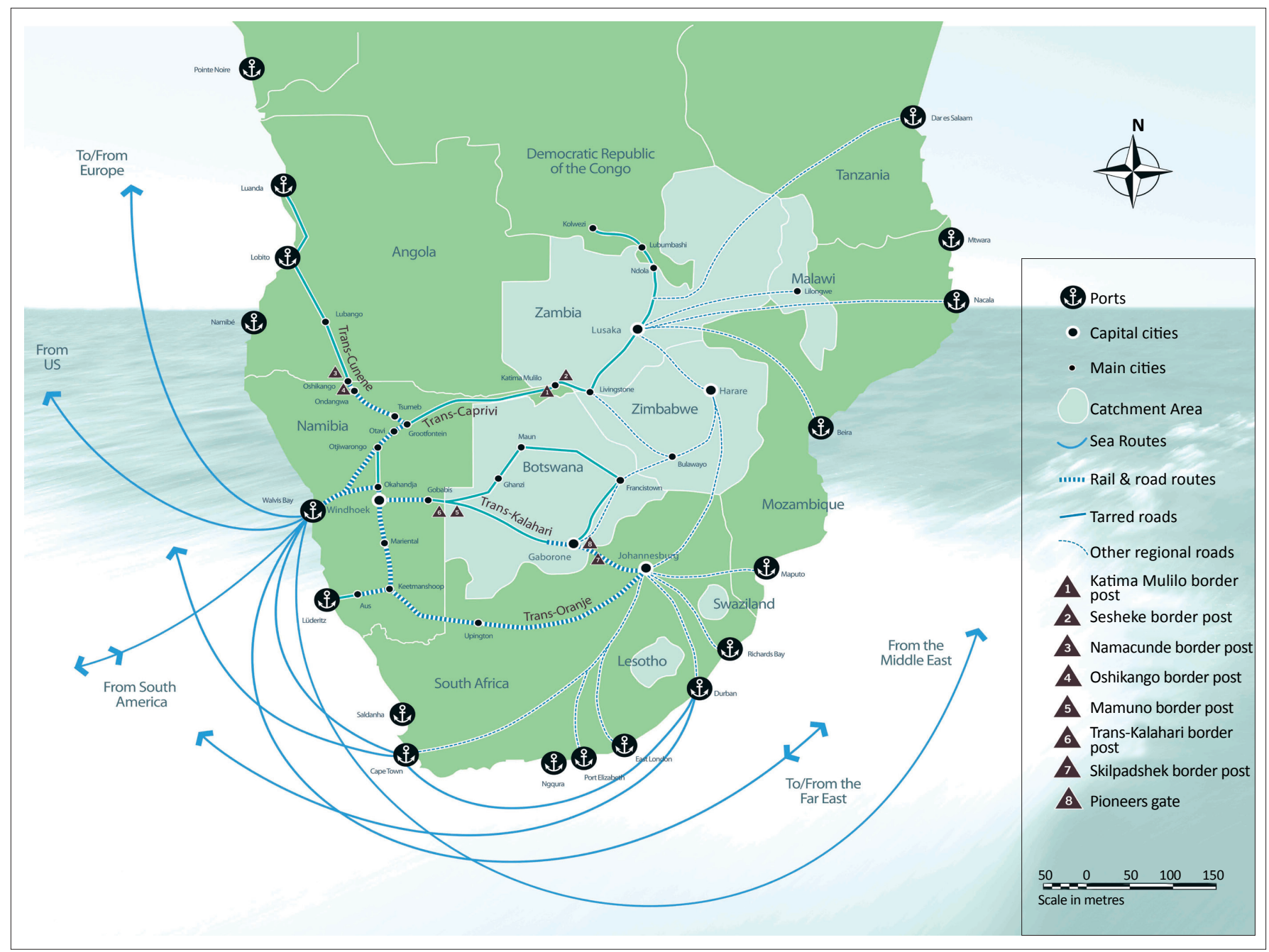

Source: Walvis Bay Corridor Group, 2012, viewed 12 July 2012, from https://www.wbcg.com.na

FIGURE 1: Map of southern Africa showing the main corridor routes.

to the continuing influence of South Africa. Typical user comments concerned sourcing and included: 'most product comes from South Africa', 'when a surge occurs the first recourse is to try to get additional suppliers from $\mathrm{SA}^{\prime}$ and 'Namibian regulations specify that $32 \%$ of fresh produce must be purchased locally, but this is artificial as many of the 'local' suppliers import much of their produce from SA anyway!' Others seemed more concerned with technical issues such as Information Technology (IT) and accounting systems: 'Customer account system, managed in SA', 'SA satellite tracking system used to check drivers or vehicles against a (manual) plan,' and 'Electronic Part Catalogues, E-Commerce Unit ordering, Dealer Management System from South Africa'.

Apart from the South Africa influence, there are other geographical factors affecting Namibian logistics, including issues related to borders. For example, 'There are Customs issues and delays at borders,' 'Border control paperwork is cumbersome and it happens often that goods (including fresh foodstuffs) are held too long because of the submission of paperwork', 'charges are applied at the borders (for example, by Botswana and Zambia)'. There are also signs of
TABLE 2: Stakeholder view of the barriers and issues affecting operations.

\begin{tabular}{ll}
\hline Barrier & Number of Comments \\
\hline The absence of an effective rail network & 12 \\
Road capacity and conditions & 10 \\
Limited harbour capacity & 5 \\
Lack of qualified staff, education and training & 16 \\
Racial issues, legislation and corruption & 7 \\
Attitude, service and culture & 8 \\
Cross-border issues and customs & 9 \\
Costs (for example, transport rates) & 8 \\
Other & $>20$ \\
\hline
\end{tabular}

potential improvement, such as being 'connected to a system that shares data like border control issues in Africa,' and 'a "Transport Observations" system is being developed that will have a database enabling the use of KPIs for factors such as; traffic volumes and border delays' (KPIs stands for key performance indicators).

\section{Barriers}

Although opinions varied both across and within the stakeholder groups, the barriers and key issues affecting the operations and development of the logistics industry in Namibia are shown in Table 2. 
The figures reflected in Table 2 shows the number of times a particular barrier was cited by a stakeholder during the interviews. As the research was qualitative rather than quantitative, the numbers cannot be regarded as a reliable indication of the importance of a barrier, but they do give an indication of their 'popularity'. Part of the ongoing work is to rank them in terms of importance as well as determining their relative impact and practicality of dealing with them. The 'other' category covers all barriers that were mentioned four times or less, they include: lack of innovation; small population or lack of critical mass; government attitude and awareness of logistics issues; Human immunodeficiency virus (HIV); airline related issues; co-operation; safety and work permits for skilled non-Namibians.

\section{Sustainability}

This was perceived from two angles: commercial continuance (the ability of the organisation to continue trading successfully) and environmental preservation. Whilst the importance of both was acknowledged, the attitude was markedly different, with business sustainability felt to be essential, but environmental action often regarded as a 'luxury'. Awareness of the need for business viability manifested itself in various ways including:

- Ongoing commercial viability - where concern was sometimes apparent. For example: 'sustainability is becoming a problem because of the distances involved and the escalating price of fuel,' and 'this year the business is good, but last year it was not sustainable'.

- Interdependence and supply chain integration - is seen as a desirable trait: 'commercial continuance or sustainability is maintained by the partnership with the main transport operator'. But, many companies are forced to operate on two distinct levels with transactional or even adversarial as well as more integrated relationships.

- Information technology - was recognised as important for a logistics business to operate successfully, especially as the commercial world becomes more 'e-business orientated'. Uptake, although covering a broad spectrum from a standalone personal computer (PC) to some form of integrated enterprise system, was generally rather limited. Very few specialist logistics systems were in evidence, which may constrain long-term sustainability.

- Costs and management - again understood as important, but operating at various levels from 'gut feel or experience' to formal management accounting systems. Whilst the former approach may give tactical success, it cannot guarantee long-term commercial sustainability.

Although the environmental aspect was usually recognised by respondents, the attitude to taking action was extremely variable.

For example, a transport company stated that environmental sustainability is key to the future for both the country and business concerns, it also saves costs and so the two concepts go 'hand in hand'. Another said that the company takes environmental considerations seriously as they are part of ensuring the future. A transport operator said that he had heard of green or environmental issues, but have never given them much thought. Another said that he is not really doing anything about the green side, but is interested in it. One more user stated simply that they are not interested in environmental issues.

Despite this seemingly low commitment to environmental action, many interviewees showed great interest in recycling and in-house green practices, especially where there was an immediate cost saving.

\section{Limitations}

This article represents the output from an exploratory study into the current state of logistics in Namibia. As with all research it is subject to limitations, which in this case includes the number of interviews carried out prior to its writing. As noted above, the interviews were targeted in a 'purposeful' manner to try to capture the views of a broad cross-section of the stakeholder groups rather than targeting a specific sector. Whilst it is not possible to ascertain the success of this tactic in statistical terms, there is considerable correlation with the findings of a contemporaneous report produced by the World Bank (World Bank 2012b). This has enabled the researchers to put together an overall picture of Namibian logistics with its strengths and weaknesses. As well as being informative in their own right, the findings can direct further investigations and serve as 'benchmarks' for future comparison as the nation, and her logistics, develop.

A further key limitation is implied by the nature of the data collected, which is qualitative rather than quantitative and is essentially opinion based. As mentioned already, findings have been validated by internal comparison using the analysed matrices and, where possible or appropriate, with available quantitative data.

\section{State of Logistics}

The opinions and data gathered by this research appear to confirm beyond reasonable doubt that logistics is not only vital to the future development of Namibia, but that the majority of stakeholders recognise its importance. This is a fact that is reinforced by the emphasis placed on logistics by the Namibian government in its latest National Development Plan, NDP_4 (National Planning Commission 2012). The degree of importance ascribed to logistics varies across the stakeholder groups, as does the understanding of its concepts. In general, the greater the understanding of logistics, the greater is the appreciation of its importance. Furthermore, the higher up the logistics 'food chain' the individual sits, the more likely they are to view the importance of logistics from the altruistic point of view of national development rather than that of self-interest and short term profit. For example, senior managers, especially those in parastatals or logistics service providers were more likely to say that logistics is essential for Namibia to develop as a trading nation, whereas owner-drivers are chiefly concerned with 'the next load' and 'putting food on the family's plates'. 
Views of the state of logistics varied, but there was consistency across the groups of stakeholders. Almost all respondents recognised that the current system works and delivers goods across the country as well as to and from its neighbours. The difference becomes apparent in the assessment of the efficiency and effectiveness of that system, its potential for development and, importantly, whether it has the capability to be an enabler of or a barrier to Namibia's future development. In many cases, such differences appeared to align either with the stakeholder category or with the size of the organisation; confirmation of the extent and significance of the latter will require further investigation (Savage et al. 2012).

In a quantitative sense the current (2012) World Bank logistics indicators rank Namibia in 69th place overall (out of 155), which places it above the other Southern African Development Community (SADC) countries, with the exception of South Africa (19th), (World Bank 2012b). This suggests that she is doing well, but has plenty of scope for improvement.

\section{Opportunities and issues}

Namibia has a key position on the west coast of southern Africa between Angola and South Africa, which are the biggest economic powers in the region. It also has the potential to service land-locked SADC countries such a Botswana and Zambia. Figure 2 shows the position of

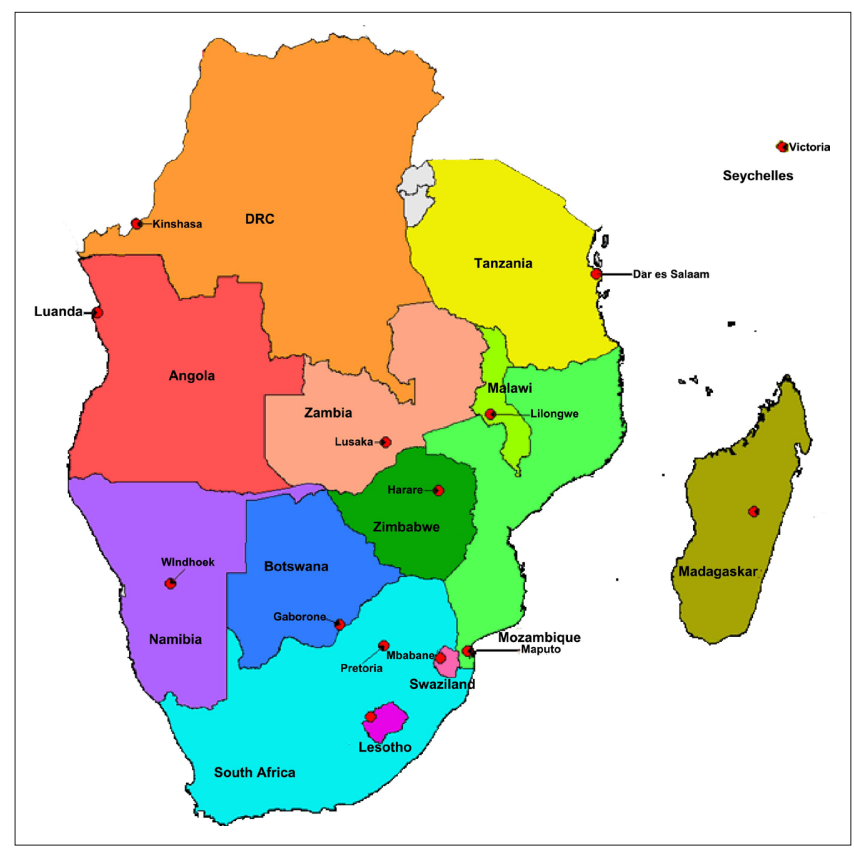

Source: OIE, 2013, Regional Representation of Africa, Annual report of the OIE Sub-Regional Representation for Southern Africa, viewed 20 July 2013, from http://www.rr-africa.oie.int/ images/sadc_map_colour_4.gif

FIGURE 2: Map of Namibia with other SADC countries.
Namibia and its proximity to the other SADC countries. This geographical positioning also imposes difficulties, because of the distances involved, which make the haulage costs and times significant. The vast size of the country, combined with the low population and very limited industrialisation, also poses problems in terms of the cost of maintaining the infrastructure. This is amplified by the high road density per head of the population and represents a significant funding problem that is reflected in the stagnation in road maintenance. Table 3 shows road density compared to head of population of SADC countries. Lack of, or slow, maintenance is a difficult issue; for example, in 2008, The Ministry of Works and Transport embarked on the complete rehabilitation of the Okahandja-Karibib road after finding that the road surface had deteriorated to such an extent that simpler patch-up jobs were no longer sufficient (Isaacs 2009). Over a year later, in 2009, Roads Authority spokesperson Audrin Mathe stated that 'the construction progress is behind the programmed schedule' (Isaacs 2009). The low critical mass in terms of trade volumes also reduces opportunities to benefit from economies of scale (Savage et al. 2012).

One way of ameliorating these problems is to boost volumes and potential revenue by increasing the through trade to the landlocked countries as well as to or from South Africa and Angola. Facilitating such trade is one of the key functions of the Walvis Bay Corridor Group. The success of their endeavours can be seen from the fact that the volume of goods moved along the corridors has grown by 33\% between 2005 and 2009, although there was a dip in 2010 (World Bank 2012b). The bulk of this increase has come from the Trans-Cunene and Trans-Caprivi corridors, as the Trans-Kalahari volumes are fairly flat. It is also interesting to note that a great deal of increase has occurred in the outbound rather than inbound volumes, despite the perceived uni-directional nature of general trade. These figures are extremely encouraging and support the views of some respondents who affirmed that the attraction of Walvis Bay comes not just from its location, but from the ease of doing business there and the fact that, until recently, there was little port congestion.

To exploit this positional opportunity further, considerable development will be required. The immediate restriction concerns the limitations of the existing port, road and rail infrastructure, which are now being placed under strain as the recent congestion suggests. The bigger prize can only be obtained by exploiting the regional location by establishing a network of logistics hubs at the port, at key Namibian locations and in the other SADC countries. This would have the potential to attract increased international shipping as well as trade, which in turn could help to change the economy of scale and provide an opportunity to address productivity issues. To be successful, a massive, co-ordinated

TABLE 3: Road density compared to population of SADC countries.

\begin{tabular}{|c|c|c|c|c|c|c|c|}
\hline \multirow[t]{2}{*}{ Road density } & \multicolumn{7}{|c|}{ Country } \\
\hline & Lesotho & Malawi & Mozambique & Namibia & South Africa & Tanzania & Zambia \\
\hline km/1000 people & 3.0 & 1.0 & 1.5 & 22.0 & 4.3 & 1.2 & 1.5 \\
\hline
\end{tabular}

Note: Adapted from AIDC Database 
infrastructural development, international co-operation and, importantly, a significant change of attitude or culture within the industry would be required. Infrastructure includes the development of terminals with intermodal capability, which would need major capital investment in port equipment, road and, especially, rail development as well as associated systems that should incorporate port management, customs and load scheduling (Savage et al. 2012). The detail of this is beyond the immediate scope of this article and would require considerable further investigation, sizing, modelling and cost analysis. The effort and costs involved in development would almost certainly require international investment and public or private partnerships. Timing is also key; even if the perfect system were to be created, there is no guarantee that the resulting connectivity would produce sufficient international traffic to ensure a payback in a viable time - but, it is certain that the longer such a development is delayed, the greater the risk of the alternative ports taking and monopolising the business.

This option seems to represent the greatest potential for the development of Namibia through its logistics industry. Whether the challenge it represents is accepted by the nation's logisticians or not, it is clear that there are a number of issues that need to be addressed for that industry to grow. The existing system works, but it lacks efficiency and does not seem to have the capacity to absorb a great deal of additional volume or to successfully compete with aggressive international competitors, whether at home or abroad. 'It is good, but not good enough' was a frequent comment made by interviewees across all of the stakeholder groups and the research underpinning this article tends to support that view.

Increased volumes of traded goods could help a move towards greater efficiency, but will not be attracted unless some basic issues are addressed. These include the attitude to service where operators and, in some cases users, do not appreciate the concept of service, especially that expected in international markets. It is essential to identify and supply the necessary service level, since:

the whole purpose of logistics is to provide customers with the level and quality of service that they require and to do so at less cost to the total supply chain (Christopher 1998:35-68).

'Globally, the successful output of customer service considerations will be a satisfied customer, which should lead to increased profitability' (Grant 2007:147-60). If Namibia wishes to compete, this challenge must be faced. To support this there is a need for education and training; both involve the process of learning, with education focusing on the knowledge and skills related to all aspects of life, and training focusing on a planned process to modify attitude knowledge and skills (Bloisi 2007). It is accepted that 'Logistics firms that train staff witness significant benefits' (Financial Times 2008). Training is needed at all levels to enable drivers, warehousemen and other operators to work as effectively and efficiently as possible, whilst protecting the goods, vehicles and equipment for which they are responsible. Education is needed to allow supervisors and managers to develop sound systems for those operators and to help their organisations evolve beyond their present level. To facilitate this training and provide interim management, many organisations make use of qualified overseas staff; this is good practice, but the government should endeavour to reduce the bureaucracy associated with such recruitment.

Connectivity, whether at a local, national or international level is essential as is interaction between stakeholders. This requires strong communication and IT systems, but these cannot be designed and will not be used effectively unless there is a better level of understanding of what is possible and needed. This again requires education and training. Systems must interact with other stakeholders and related service providers such as customs and the parastatals.

Parastatals and similar bodies must be integrated into all project plans. It is easy to criticise their apparent recalcitrance, slowness and siloism, but unless they and private companies are made jointly responsible, projects will always fail or arrive at sub-optimal solutions. It is also essential that projects are implemented, rather than simply mooted. Further, their output must be subject to evaluation, monitoring and review. Without a well-thought-out monitoring and evaluation plan, one cannot tell whether the project has achieved its objectives. Furthermore, without feedback, none of the parties concerned with project outcomes could make appropriate, informed decisions about whether and how to adjust the design or implementation arrangements to better achieve the intended objectives (Mosse \& Sontheimer 1996). This will require education and may necessitate changes in management appointment and practise in both the public and private sectors, but again, unless such measures are taken, success will be limited.

There is a need for specialist systems, some of which can be owned and bring benefits on an individual basis, but others will only be effective if they are shared, ideally nationally, by groups of operators, or companies with an overarching view such as 3PL or 4PL. Such 'community' systems can be costly to initiate and require open co-operation, but have great potential to address national issues, such as improving vehicle usage. Some issues, however, can only be addressed at the national or international level, but they are essential to facilitate regional and international trade and so must be tackled in parallel with the 'pure logistics' issues.

Perhaps the final piece of the jigsaw is the green agenda. As Mangan, Lalwani and Butcher (2008:268-280) suggested, one must consider the question; 'How can a firm survive and grow in a sustainable manner without having adverse impacts on future generations, and specifically; what is the role of logistics and SCM in this context?' As revealed in the findings, there is a tendency to postpone addressing environmental issues in favour of projects with a more immediate financial benefit. This is a very short-sighted approach because: green thinking often brings financial benefits; legislation from neighbouring countries may force the issue; international requirements may make non-compliant companies non-competitive; much of Namibia's attraction as a tourist venue is its flora, fauna 
and lack of pollution (National Planning Commission 2012). Logisticians, like everyone else, have a duty to improve efficiency and effectiveness without jeopardising the future of the country and ultimately, the planet.

\section{Future work}

This article represents the findings of the first phase of a study. The next stage will include further interviews. By increasing the sample size, more depth will be given to some stakeholder groups and the division of these into further subcategories will be possible if justified. The additional data should allow the researchers to determine whether factors such as company size are indeed significant.

In addition to this, Phase I results have suggested a number of areas for dedicated research projects, including: rail and intermodal transport; 'green logistics' and the environment; 'hubs' and supply chain linkages; logistics-related information technology (including customs and border systems); and brokerage systems. These would require carefully focused projects with more quantitative data. There may also be scope for some 'soft skills' type work in areas such as attitude assessment, change management, education or cultural issues and their impact.

Overall, one can conclude that Namibia's logistics industry serves its purpose at the moment, but cannot afford to stand still and must address the issues identified in this article. If it does, it has a good opportunity to become a gateway to southern Africa and reap the rewards in terms of both trade and inbound investment. If it fails to do so, does so halfheartedly, or is too late, it will simply stagnate.

\section{Conclusion}

This article seeks to address the overall research question: 'What is the current state and potential for the development of Logistics in Namibia?' The aforementioned sections gave key conclusions based on the research within the limitations stated. Nota Bene, additional details are available in a full report entitled 'Logistics in Namibia: Issues and challenges' (Savage, Fransman \& Jenkins 2012).

\section{Acknowledgements Competing interests}

The authors declare that they have no financial or personal relationship(s) that may have inappropriately influenced them in writing this article.

\section{Authors' contributions}

A.J. (University of Huddersfield) wrote the majority of the literature review, this was updated with local data by L.F. (Polytechnic of Namibia). A.J. also wrote the initial draft of the methodology section. C.S. (Polytechnic of Namibia) wrote the initial draft of the findings, results, conclusions, etc. These were then revised by A.J. and L.F., the other two authors.

\section{References}

African Development Bank, 2007, African Economic Outlook: Namibia, AIBD, Abidjan. Air Namibia, 2012, Air Namibia, viewed 10 September 2012, from www.airnamibia. com.na

Bloisi, W., 2007, An introduction to Human Resource Management, McGraw-Hill, London.

Blumberg, B., Cooper, D. \& Schindler, P., 2011, Business Research Methods, McGrawHill, London.

Christopher, M., 1998, Logistics and Supply Chain Management, 2nd edn., Prentice Hall (FT), Harlow.

CIA, 2012, Factbook: Namibia, viewed 10 July 2012, from https://www.cia.gov/library/ publications/the-world-factbook/geos/wa.html

Cilliers, W. \& Nagel, P., 1994, Logistics Trends in South Africa, International Journal of Physical Distribution \& Logistics Management, 24(7), 4-14. http://dx.doi. org/10.1108/09600039410070948

Clarke, A., 2003, Research and the policy-making process, in G. Gilbert, Researching social life, Sage Publications, London.

Clerck, G., 2008, Industrial relation in Namibia since independence: Between neoliberalism and neo-corporatism? Employee Relations, 30(4), 355-71. http:// dx.doi.org/10.1108/01425450810879349

Fielding, N. \& Thomas, H., 2003, Qualitative Interviewing, in G. Gilbert, Researching social life, Sage Publications, London.

Financial Times, 2008, Logistics industry training under fire, Financial Times, 05 January.

Grant, D., 2007, Using services marketing strategies for logistics customer service, in D. Waters, Global Logistics, Kogan Page, London, pp.147-160.

Isaacs, D., 2009, Work on Karibab road resumes. [Newspaper article] Windhoek: The Namibian, viewed 19 February 2013, from, http://www.namibian.com.na/index. php?id=28\&tx_ttnews\%5Btt_news\%5D=2170\&no_cache $=1 \% 20$

Mangan, J., Lalwani, C. \& Butcher, T., 2008, Global logistics and supply chain management, 1st edn., John Wiley \& Sons Ltd, Chichester.

Mosse, R. \& Sontheimer, S., 1996, Performance monitoring indicators handbook, Technical paper 334, World Bank, Washington DC.

Nadin, S. \& Cassell, C., 2004, Using Data Matrices, in C. Cassell \& G. Symon, Essential Guide to Qualitative Methods in Organizational Research, Sage Publications, London.

NAMPORT, 2012, Namibian Ports Authority, viewed 12 September 2012, from www. namport.com.na

National Planning Commission, 2008, National Planning Commission, vol 1, viewed 24 October 2012, from www.npc.gov.na/docs/NDP3_Executive_Summary.pdf

National Planning Commission, 2012, Namibia's Fourth National Development Plan, NDP 4. Windhoek: National Planning Commission Republic of Namibia.

NEPRU, 2010, Namibian Economic Review and Prospects for 2010, viewed 13 July 2012, from www.hsf.org.na/download/EconomicRevJan10.pdf

Republic of Namibia, 2004, Namibia Vision 2030: Policy Framework for the Long-Term National Development of the Country, Office of the President, Windhoek.

OIE, 2013, Regional Representation of Africa, Annual report of the OIE Sub-Regional Representation for Southern Africa, viewed 20 July 2013, from http://www.rrafrica.oie.int/images/sadc_map_colour_4.gif

Oxford Dictionaries, 2012, oxforddictionaries.com. viewed 17 July 2012, from http:// oxforddictionaries.com/definition/english/parastatal?q=parastatal

Saunders, M., Lewis, P. \& Thornhill, A., 2007, Research methods for business students, Financial Times/Prentice Hall, Harlow.

Savage, C.J., Fransman, L. \& Jenkins, A.K., (2012), Logistics in Namibia: Issues and challenges, The Polytechnic of Namibia, Namibia.

TransNamib, 2012, TransNamib Holding Ltd, viewed 10 September 2012, from www. transnamib.com.na

Voordijk, H., 1999, Obstacles and preconditions for logistics and manufacturing improvement in Africa - a case study, International Journal of Operations \& Production Management, 19(3), 293-307. http://dx.doi.org/10.1108/01443579910249723

Walvis Bay Corridor Group, 2012, viewed 12 July 2012, from https://www.wbcg.com.na

World Bank, 2009, Namibia Country Brief, viewed 10 July 2012, from http://site.ebray. com/lib/uoh http://site.ebray.com/lib/uoh

World Bank, 2012a, Gini Index, viewed 05 July 2012, from http://data.worldbank.org/ indicator/SI.POV.GINI/

World Bank, 2012b, Regional transport \& trade logistics in Namibia: A policy note. 